This is the pre-peer reviewed version of the following article: Waleed Mohammed-Saeid, Deborah Michel, Ildiko Badea, Anas ElAneed. (2017), Rapid and Simple Flow Injection Analysis-Tandem Mass Spectrometric (FIA-MS/MS) Method for the

Quantification of Melphalan in Lipid-Based Drug Delivery System. Rapid Commun. Mass Spectrom., 31(18): 1481-1490, which

has been published in final form at doi: $10.1002 / \mathrm{rcm}$.7926. This article may be used for non-commercial purposes in accordance with Wiley Terms and Conditions for Self-Archiving.

\title{
Rapid and Simple Flow Injection Analysis-Tandem Mass Spectrometric (FIA-MS/MS) Method for the Quantification of Melphalan in Lipid-Based Drug Delivery System.
}

\author{
Waleed Mohammed-Saeid ${ }^{1,2}$, Deborah Michel $^{1}$, Ildiko Badea ${ }^{1}$, Anas El-Aneed ${ }^{1 *}$.
}

1. College of Pharmacy and Nutrition, University of Saskatchewan, Saskatoon, SK, S7N 5E5, Canada.

2. College of Pharmacy, Taibah University, Madina, Saudi Arabia

* To whom correspondence should be addressed: anas.el-aneed@ usask.ca; phone: +1-306-966-2013

\begin{abstract}
The use of the anticancer drug melphalan is limited due to its poor water solubility. To address such limitation, it is incorporated within a novel delivery system using $\beta$-cyclodextrin-gemini surfactants (18:1ßCDg). Herein, two fast and simple FIA-MS/MS methods are developed for the quantification of melphalan (Mel) within the drug delivery system so that the solubilization efficiency of the system can be assessed. FIA-MS/MS methods are developed using a triple quadrupole-linear ion trap mass spectrometer, equipped with electrospray ionization (ESI) in the positive ion mode. A deuterated form of melphalan (melphalan-d8) was used as an internal standard (IS). The methods were validated according to the FDA guidance. A linearity in the range of $2-100 \mathrm{ng} / \mathrm{mL}$ and accuracy and precision below $15 \%$ were observed for all standard points and quality control samples. The intra- and inter-day variations, freeze-thaw stability were within the acceptable range according to the criteria set by regulatory guidelines. On the other hand, other stability measures, such as room temperature stability and long term stability did not meet the required guidelines in some cases, indicating the need for quick sample analysis upon preparation. Such a fact could have been overlooked if full method validation was not performed. The developed methods were applied to determine the encapsulation/solubilisation of [18:1 $\beta \mathrm{CDg} \backslash \mathrm{Mel}]$ delivery system. 18:1 $\beta \mathrm{CDg}$ enhances the aqueous solubility of melphalan without the need for co-solvent. The highest melphalan solubility was observed at the $18: 1 \beta \mathrm{CDg} \backslash \mathrm{Mel}$ complex molar ratio of $2: 1$. This study demonstrated that a fast analysis for the purpose of quantifying a chemically unstable drug, such as melphalan is feasible and important for the development of commercial dosage forms.
\end{abstract}

Keywords: Flow Injection Analysis, Mass Spectrometry MSMS, Melphalan, $\beta$-cyclodextrin Drug Delivery 


\section{Introduction}

Several effective chemotherapeutic agents, such as melphalan, show unfavourable solubility or stability due to their physiochemical properties that affect their therapeutic use. ${ }^{1-3}$ Melphalan (Lphenylalanine mustard) (Figure 1-A) is an alkylating agent primarily used in the management of multiple myeloma and as an adjunctive therapy in regionally in-transit metastatic melanoma. ${ }^{4}$ It is a lipophilic drug with low aqueous solubility, requiring the use of a co-solvent (namely, propylene glycol) for parenteral administration. Propylene glycol can cause adverse effects when used in high concentrations, including, nephrotoxicity, cardiac arrhythmia, and metabolic acidosis. ${ }^{5}$ In addition to poor solubility, melphalan shows minimal chemical stability in aqueous medium as it hydrolyzes into hydroxymelphalan. ${ }^{6}$ Therefore, attempts to improve melphalan's solubility and stability were conducted by either chemical modifications or by engineering novel drug delivery systems, such as nano-systems. ${ }^{7-10}$

Nanotechnology is being applied for developing novel therapies that can improve the solubility of poorly soluble drugs. ${ }^{11}$ For example, cyclodextrin-based drug delivery systems have been widely investigated to improve the delivery of melphalan as well as other chemotherapeutics. ${ }^{12-15} \beta$-Cyclodextrin $(\beta-C D)$ is a natural product with low toxicity. ${ }^{16}$ It has the ability to enhance the delivery of hydrophobic drugs by forming gust-host complexes. ${ }^{16} \beta-\mathrm{CD}$ has cyclic ring structure containing seven $\mathrm{D}-(+)$ glucopyranose units attached by a-(1,4) glucosidic bonds which create a lipophilic inner cavity and hydrophilic outer surface. Such architecture creates a moiety capable of interacting with a large variety of guest molecules to form non-covalent inclusion complexes. To enhance the drug delivery capacity of the $\beta-\mathrm{CD}$, we conjugated the molecule to gemini surfactants moieties. Gemini surfactants are composed of two hydrophobic portions, commonly quaternary amines, and two hydrophobic portions with the two polar groups connected via a spacer region. They have the ability to interact electrostatically with the negatively charged cell surface, enhancing cellular uptake of the delivery system ${ }^{17}$.

The resulting conjugate, $18: 1-7 \mathrm{~N} \beta \mathrm{CD}-18: 1(18: 1 \beta \mathrm{CDg})$ (Figure 1-C) combines the encapsulation properties of $\beta-\mathrm{CD}$ and the cell-penetrating ability of cationic gemini surfactants. ${ }^{18-20}$ This novel drug 
delivery system can incorporate lipophilic drugs, such as melphalan, into the $\beta$-CD moiety and form nanoplatform. ${ }^{21}$ Recently, we showed the efficiency of $\beta$-CD-modified gemini surfactant $(12 \beta C D g)$ in improving the delivery of melphalan in melanoma cell line. ${ }^{22}$ The $\mathrm{IC}_{50}$ of melphalan improved significantly and demonstrated efficiency in melphalan- resistant melanoma. To optimize the stability of the complex and to maximize the solubilisation efficiency, various analytical methods were developed. Higuchi and Connors described an analytical approach to study the $\mathrm{CD} / \mathrm{drug}$ solubility relationship known as the phase-solubility method. ${ }^{23}$ This method examines the effect of the solubilizer (CD or a ligand) on the drug being solubilized (the substrate). Therefore, the development of analytical methods to determine the encapsulation/solubilisation efficiency of the $\beta$-CD moiety is critical in the development of efficient $\beta$-CD modified drug delivery system.

Numerous high-performance liquid chromatography (HPLC) analytical methods have been developed to quantify melphalan in pharmaceutical and biological systems for pharmacokinetic and quality control studies. ${ }^{24-30}$ For instance, Cummings and co-workers described an HPLC method for the determination of nitrogen mustard compounds, including melphalan, in plasma samples after chemical derivatization process with diethyldithiocarbamic acid (DDTC). ${ }^{29} \mathrm{C}_{18}$ column was used with a linearity range of $0.1-100 \mathrm{~g} / \mathrm{mL}$. However, this method lacked sensitivity and required long sample preparation time (30 min) with a run time of 14.6 minutes. Pinguet et al developed a simplified HPLC method, requiring 3.3. min run time. ${ }^{30}$ Despite improvements, the lower limit of quantification (LLOQ) at 20 $\mathrm{ng} / \mathrm{mL}$ may not be sufficient for many pharmaceutical applications. To improve melphalan quantification, mass spectrometry (MS) have also been used. ${ }^{31-35}$ A rapid HPLC-MS method for the quantification of melphalan in serum and plasma demonstrated a retention time of $\approx 2$ min with LLOQ of $2 \mathrm{ng} / \mathrm{mL} .^{32}$ However, the method requires a relatively complicated extraction procedure with specialized instrumentation (96 well solid phase extraction (SPE) blocks). The use of HPLC-tandem mass spectrometry (MS/MS) was reported by Mirkou and colleagues using two different HPLC conditions/columns and two extraction methods. ${ }^{33}$ In the first method, a cold methanol protein 
precipitation is applied prior to injection onto a $\mathrm{C}_{18}$ column while the second one was based on solid phase extraction followed by hydrophilic interaction chromatography (HILIC)-MS/MS. The linearity of the methods were $1-500 \mathrm{ng} / \mathrm{mL}$ and $25-200 \mathrm{ng} / \mathrm{mL}$, respectively with $\approx 7$ min retention time in both cases.

Despite the wide use of HPLC-MS, a simpler MS-based approach for quantification is flow injection analysis-tandem mass spectrometry (FIA)-MS/MS in which the analytical column is removed and quantification is reliant on MS response in multiple reaction monitoring mode (MRM). (FIA)MS/MS has been widely utilized as a simple and high throughout methods in comparison to LChyphenated techniques. It provides cost and time effective strategy that have been explored for the analysis of pharmaceuticals in different matrices. ${ }^{36-39}$ For example, a fully validated simple FIA-MS/MS method was recently developed to quantify metformin in dog serum. ${ }^{36}$ The method was simple and fast ( 2 min run time), achieving a sensitivity comparable to the relatively complicated conventional HPLCMS/MS methods. ${ }^{40,41}$ The main shortcoming of FIA, however, is seen in complex matrices, particularly with multi-analyte analysis in which the linearity range of the method can be affected. In addition, the removal of the LC column can cause saturation of the MS detector with either the analyt(s) or matrix components, which can negatively affect method sensitivity. ${ }^{42}$ However, the advances in sample extraction techniques and in ionization efficiency (especially in ESI and nano-ESI) can overcome such hurdles, which is reflected in the large number of methods employing FIA. ${ }^{43}$

In this paper, we developed and validated a rapid and simple FIA-MS/MS methods that were applied for the quantification of melphalan in 18:1ßCDg surfactant formulations. The methods were used to assess the solubilisation efficiency of $18: 1 \beta C D g$ as a potential drug delivery system for melphalan. 
(A)

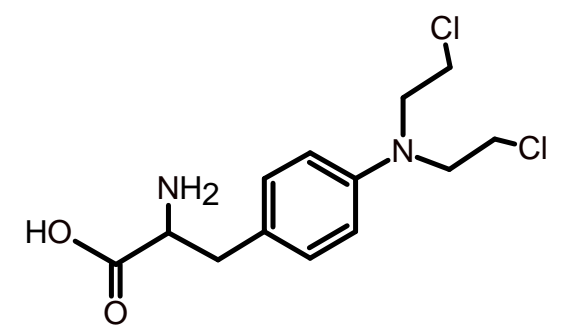

(B)

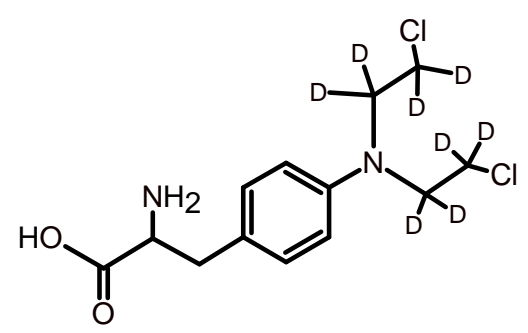

(C)

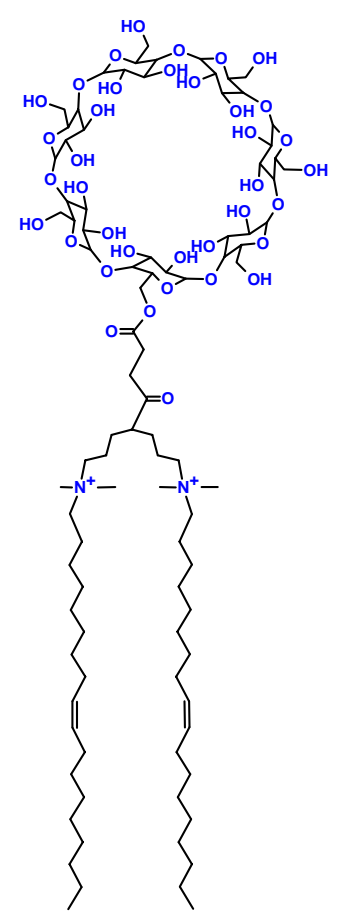

Figure 1: chemical structure of (A) melphalan, (B) melphalan-d8 and (C) 18:1-7N $\beta C D-18: 1$ $(18: 1 \beta C D g)$ gemini surfactant 


\section{Material \& Methods}

\subsection{Materials and apparatus}

Melphalan (Mel, 99 \% Purity) was purchased from Sigma-Aldrich (Oakville, ON, Canada). Melphalan-d8 dihydrochloride (Mel-d8), used as internal standard (IS), was purchased from Toronto Research Chemicals Inc (Toronto, ON, Canada). Synthesis and characterization of 18:1-7N $\beta C D-18: 1$ gemini surfactant was previously described..$^{20,21}$ Formic acid was purchased from EMD (Gibbstown, NJ,USA). Water (LC-MS grade), acetonitrile (LC-MS grade) and Dimethyl Sulfoxide DMSO (Certified ACS) were purchased from Fisher (Ottawa, ON, CA). Chemical structure of the drug, IS and 18:1 $\beta C D g$ are shown in Figure 1.

\subsection{Standard Preparation}

\subsubsection{Method \#1:}

Stock solutions of melphalan $(1 \mathrm{mg} / \mathrm{mL})$ was prepared in $10 \%$ acidified ethanol $(0.1 \% \mathrm{HCl})$, to achieve complete aqueous solubility, and stored at $-80^{\circ} \mathrm{C}$. Fresh standard solutions were prepared daily by serial dilutions in water (LC/MS grade) to eight standard points in a range from $3 \mathrm{ng} / \mathrm{mL}$ to $100 \mathrm{ng} / \mathrm{mL}$. The stocks of standard solutions were stored at $-80{ }^{\circ} \mathrm{C}$ for method validation. A stock solution of Melphalan$\mathrm{d} 8(1 \mathrm{mg} / \mathrm{mL})$ in DMSO was prepared and stored at $-20{ }^{\circ} \mathrm{C}$. Working stock of melphalan-d8 $(4 \mu \mathrm{g} / \mathrm{mL}$ in DMSO) was prepared daily and $10 \mu \mathrm{L}$ was added to each standard and sample to a final concentration of $40 \mathrm{ng} / \mathrm{mL}$. The purpose of this method is to compare the solubility of melphalan between acidified aqueous solution and the $18: 1 \beta C D g$ gemini surfactant formulations (i.e. control).

\subsubsection{Method \#2:}

Method\#2 was developed to quantify the analyte in lipid-based drug delivery systems. Stock solution of melphalan $(1 \mathrm{mg} / \mathrm{mL})$ was prepared in acidified ethanol $(0.1 \% \mathrm{HCl})$. An appropriate volume of melphalan solution was mixed with $18: 1 \beta C D g$ gemini surfactant aqueous solution to yield a final molar ratio of 2:1

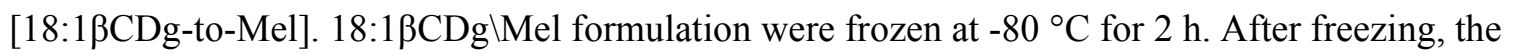


formulation was transferred to a Labconco ${ }^{\circledR}$ Freezone Plus 6 L cascade freeze dryer (Labconco, Kansas City, MO,USA) at $-80^{\circ} \mathrm{C}$ and $0.03 \mathrm{mBar}$ vacuum and lyophilized for $24 \mathrm{~h}$. Lyophilized formulations were rehydrated to a final concentration of $1 \mathrm{mg} / \mathrm{mL}$ melphalan. Eight standard points in a range from 3 $\mathrm{ng} / \mathrm{mL}$ to $100 \mathrm{ng} / \mathrm{mL}$ (melphalan) were prepared. Melphalan-d8 (IS) were spiked in all standards at final concentration of $40 \mathrm{ng} / \mathrm{mL}$. The stocks of standard solutions were stored at $-80{ }^{\circ} \mathrm{C}$ for method validation.

\subsection{Mass Spectrometry conditions}

FIA-MS/MS methods were developed and validated using a 1200 Agilent High Performance Liquid Chromatography (HPLC) system (Mississauga, ON, CA) interfaced by connector to an ABSciex QTRAP 4000, a hybrid quadrupole linear ion trap mass spectrometer (Q-LIT), equipped with a Turbo-V IonSpray ${ }^{\circledR}$ electrospray ionization (ESI) source (Concord, ON, CA). ABSciex Analyst software (Version 1.6.0) was used for system control and quantification.

Sample injection was performed using 1200 Agilent auto-injector set to $4{ }^{\circ} \mathrm{C}$ and $2 \mu \mathrm{L}$ of each sample was delivered with isocratic mobile phase consisting of water/acetonitrile (50:50, v/v) with $0.1 \%$ formic acid at a flow rate of $0.2 \mathrm{~mL} / \mathrm{min}$ for a run time of 2 minutes. Multiple reaction monitoring (MRM) was achieved using (ESI) source in the positive ion mode. Source temperature was set to $600 \mathrm{C}$, ion spray voltage (ISV) $5500 \mathrm{~V}$, curtain gas (CUR) 40, nebulizer gas (GS1) 40, heater gas(GS2) 40, collision gas (CAD) 6 and using an exit potential of $16 \mathrm{~V}$ for all MRM transitions. Dwell time for all transitions was $150 \mathrm{~ms}$ at unit resolution. Nitrogen was used as the gas for all cases. Table 1 summarizes the monitored ion transitions, for both the analyte and the internal standard, and the corresponding MS conditions. Acceptance criteria for the ratio between the quantifier/qualifier ions was set at $\pm 20 \%$ as recommended by the Commission of the European communities ${ }^{44}$. In fact all our acquired data showed variations less than $7 \%$ expect for two points showing $13 \%$ and $18 \%$. 


\begin{tabular}{|l|c|c|c|c|}
\cline { 2 - 5 } \multicolumn{1}{c|}{} & \multicolumn{2}{c|}{ Melphalan } & \multicolumn{2}{c|}{ Melphalan-d8 (IS) } \\
\cline { 2 - 5 } \multicolumn{1}{c|}{$\begin{array}{c}305 \rightarrow 168 \\
\text { (Quantification) }\end{array}$} & $\begin{array}{c}305 \rightarrow 246 \\
\text { (Conformation) }\end{array}$ & $\begin{array}{c}314 \rightarrow 172 \\
\text { (Quantification) }\end{array}$ & $\begin{array}{c}314 \rightarrow 254 \\
\text { (Conformation) }\end{array}$ \\
\hline De-clustering potential (DP) & 55 & 50 & 56 & 52 \\
\hline Collision energy (CE) & 45 & 33 & 38 & 35 \\
\hline Collision exit potential (CXP) & 16 & 16 & 16 & 16 \\
\hline
\end{tabular}

Table 1: MRM transitions for melphalan and melphalan-d8 (IS) and optimized MS conditions

\subsection{Method Validation}

FDA Guidance for Bioanalytical Method Validation was used as a guideline to validate both FIA-MS/MS methods, ${ }^{45}$ to ensure the a validity of the quantitative data. The following parameters were evaluated for method validation: selectivity, accuracy, precision, sensitivity, recovery, reproducibility, matrix effect, dilution integrity and stability.

Selectivity was tested at the lower limit of quantification $(3 \mathrm{ng} / \mathrm{mL})$ for the ability to distinguish the analyte in the presence of other components in the formulation. Five sets of the formulation were used.

A standard (calibration) curve of eight concentration points, ranging from $3 \mathrm{ng} / \mathrm{mL}$ to $100 \mathrm{ng} / \mathrm{mL}$, were constructed for each method by determining the best fit of peak area ratios (peak area ratio of the analyte to internal standard) versus the analyte concentration. A linear regression analysis weighing the standard curve with $1 / \mathrm{X}$ was applied for best fit.

To evaluate the accuracy and precision of the standard curve, five replicate of each quality control (QC) sample $(\mathrm{LLOQ}=3 \mathrm{ng} / \mathrm{mL}$, low QC $(\mathrm{LQC})=9 \mathrm{ng} / \mathrm{mL}$, middle $\mathrm{QC}(\mathrm{MQC})=35 \mathrm{ng} / \mathrm{mL}$ and high QC $(\mathrm{HQC})=80 \mathrm{ng} / \mathrm{mL}$ ) were used. Accuracy of QCs passed only if the mean values of the QC were within $15 \%$ of the actual concentration except for (LLOQ) where it should be $\pm 20 \%$ of the nominal value. For precision, each value of QC replicates must not exceed $15 \%$ of the coefficient of variation $(\mathrm{CV})$ except for (LLOQ) where is should be $\pm 20 \%$ of the CV. Inter- and intra-day accuracy and precision were also evaluated in a similar manner. 
Dilution integrity was evaluated to assess the effect of dilution on the accuracy and precision of undiluted sample. Formulations were prepared without the drug as described above and spiked with $1 \mu \mathrm{g} / \mathrm{mL}$ of the drug. Spiked samples were then diluted with acidified water to $100 \mathrm{ng} / \mathrm{mL}(10 \mathrm{x})$ and $10 \mathrm{ng} / \mathrm{mL}(100 \mathrm{x})$.

The stability of melphalan in formulation matrix was tested using freshly prepared calibration curve and QC samples for a) short-term stability (at bench top and auto-sampler); b) long-term stability at $-80{ }^{\circ} \mathrm{C}$; and c) freeze / thaw stability. A set of five replicates of each QC were prepared for each stability evaluation. For bench top short-term stability, samples stored at room temperature for 12 and $24 \mathrm{hr}$ and re-analyzed. Another set of QC samples were prepared and analyzed then stored in the auto-sampler for $24 \mathrm{~h}$ at $4{ }^{\circ} \mathrm{C}$ and reinjected. QC samples for the freeze / thaw stability were stored in the $-80{ }^{\circ} \mathrm{C}$ freezer and were subjected to three freeze-thaw cycles. The samples were allowed to thaw completely and

remained at room temperature for at least $1 \mathrm{~h}$. Then samples were re-analyzed and returned to the $-80{ }^{\circ} \mathrm{C}$ freezer for the next freeze-thaw cycle. The long-term stability was conducted on QC samples stored at $-80^{\circ} \mathrm{C}$ for 30 days.

\subsection{Method Application, Solubility Evaluation}

The developed methods were used to determine the solubilizing efficiency of cyclodextrin-modified gemini surfactant. 18:1 $\beta \mathrm{CDg} \backslash \mathrm{Mel}$ formulations were prepared in different carrier-to-drug molar ratios $(0: 1,1: 1,2: 1,3: 1$ and 5:1) as shown in Table 2. First, gemini surfactant stock solutions were prepared. Then, $1 \mathrm{mg}$ of melphalan powder was added to each vial and placed in orbital shaker for 1 hour. Samples were subsequently lyophilized as described above. Upon freeze drying, samples were re-hydrated with 1 $\mathrm{mL}$ water and filtered through $0.45 \mu \mathrm{M}$ syringe filter to remove any insoluble melphalan. Samples were diluted 100X in acidified water and IS spiked in each sample to a final concentration of $40 \mathrm{ng} / \mathrm{mL}$. For samples containing free drug, Method 1 was used to quantify the analyte and for samples containing melphalan:18:1ßCDg complex, Method 2 was used. 


\begin{tabular}{|c|c|c|c|}
\hline $\begin{array}{l}\text { Formulation } \\
\text { ID }\end{array}$ & $\begin{array}{l}\text { Molar Ratio } \\
\text { 18:1 } \beta \mathrm{CDg} / \mathrm{Mel}\end{array}$ & $\begin{array}{l}\text { Amount of 18:1 } \beta C D g \\
\text { mg (Molarity) }\end{array}$ & $\begin{array}{l}\text { Amount of melphalan } \\
\text { mg (Molarity) }\end{array}$ \\
\hline 1 & $0: 1$ & 0 & $1(3.28 \mathrm{mM})$ \\
\hline 2 & $1: 1$ & $6.49(3.28 \mathrm{mM})$ & $1(3.28 \mathrm{mM})$ \\
\hline 3 & $2: 1$ & $12.98(6.56 \mathrm{mM})$ & $1(3.28 \mathrm{mM})$ \\
\hline 4 & $3: 1$ & $19.47(9.84 \mathrm{mM})$ & $1(3.28 \mathrm{mM})$ \\
\hline 5 & $5: 1$ & $32.41(16.4 \mathrm{mM})$ & $1(3.28 \mathrm{mM})$ \\
\hline
\end{tabular}

Table 2: molar rations of 18:1 $\beta \mathrm{CDg} \backslash$ Melphalan formulations evaluated in this work

\section{Results and Discussion}

\subsection{Method development and selectivity}

The main purpose of this work is to develop fast and simple FIA-MS/MS quantification methods for melphalan by removing the need for chromatographic separation while solely utilizing the MRM capability of the MS instrument, ensuring specificity and selectivity. In addition, no extraction process was needed for the drug from the formulation, indicating the simplicity of the analytical procedure. The methods were developed to assess the novel $\beta$-CD modified drug delivery system $18: 1 \beta C D g$ and for quality control purposes.

To ensure the robustness of the methods that are reliant only on the MS, the following strategies were adopted. First, two MRM transitions were selected and the monitored product ions for melphalan were diagnostic with relatively high abundance [Figure 2]. In addition, the MS conditions (i.e. DP, CE and CXP) were optimized for each MRM transition to ensure the ions stability and abundance [Table 1].

Second, a deuterated melphalan analogue that bears 8 deuterium atoms (melphalan-d8) was used as an internal standard to account for any possible effects of formulation excipients/drug delivery system on the ionization and quantification of the drug. The internal standard (melphalan-d8) was spiked into standard curve samples, the QCs, and experimental samples to give a final concertation of $40 \mathrm{ng} / \mathrm{mL}$ prior to sample analysis. The similarity in the physicochemical properties of the deuterated internal standard (melphalan-d8) to the analyte (melphalan) confirmed the validity of the data and prevented any crosstalk between the two molecules. Figure 2 shows the MS/MS spectra of melphalan (Figure 1A) and the internal 
standard melphalan-d8 (Figure 1B) and the proposed structures of the selected product ions. The ion observed at $\mathrm{m} / \mathrm{z} 168$ for melphalan and at $\mathrm{m} / \mathrm{z} 172$ for melphalan-d8 are the most abundant ions in the spectra and they were selected as the MRM transition for quantification. The second MRM transition, 305 $\rightarrow 246$ for melphalan and $314 \rightarrow 254$ for melphalan-d8, were used as a confirmation transitions.

Finally, two FIA-MS/MS methods were developed and validated in this work: method\#1 to quantify melphalan in aqueous solution with the use of a co-solvent and method\#2 to quantify the drug from 18:1 $\beta C D$ delivery system to eliminate any possible interferences caused by formulation excipients. A typical FIA-MS/MS chromatogram for a double blank of $18: 1 \beta C D g$ drug delivery system (control: not spiked with melphalan nor internal standard) is presented in Figure 3A. It shows no interference from the drug delivery system components at the analyte/internal standard retention time $(0.17 \mathrm{~min})$ or during the full run time (2 $\mathrm{min})$. Similar observations were reported during the construction of standard curve at different melphalan concentrations. 


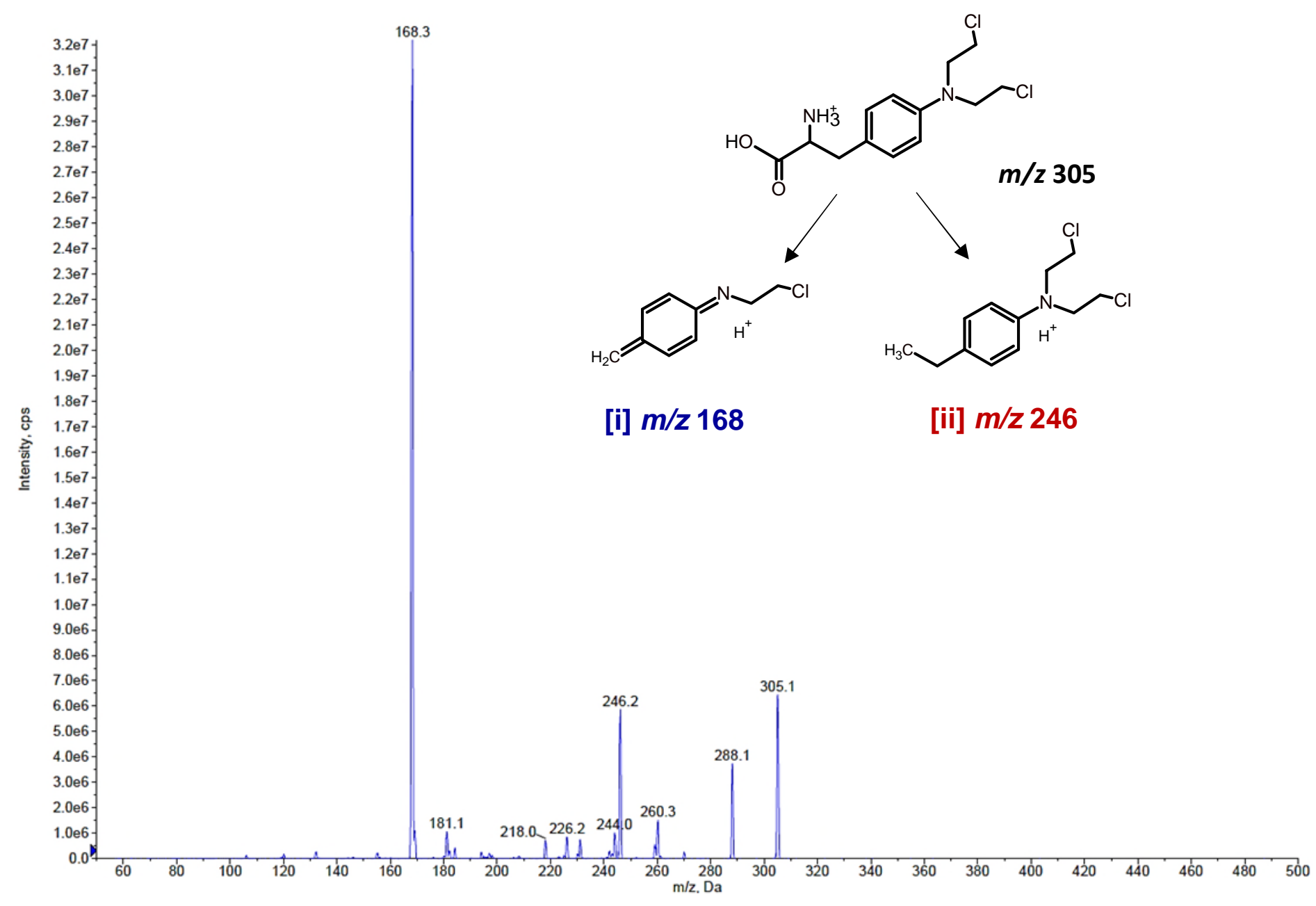

(A) 


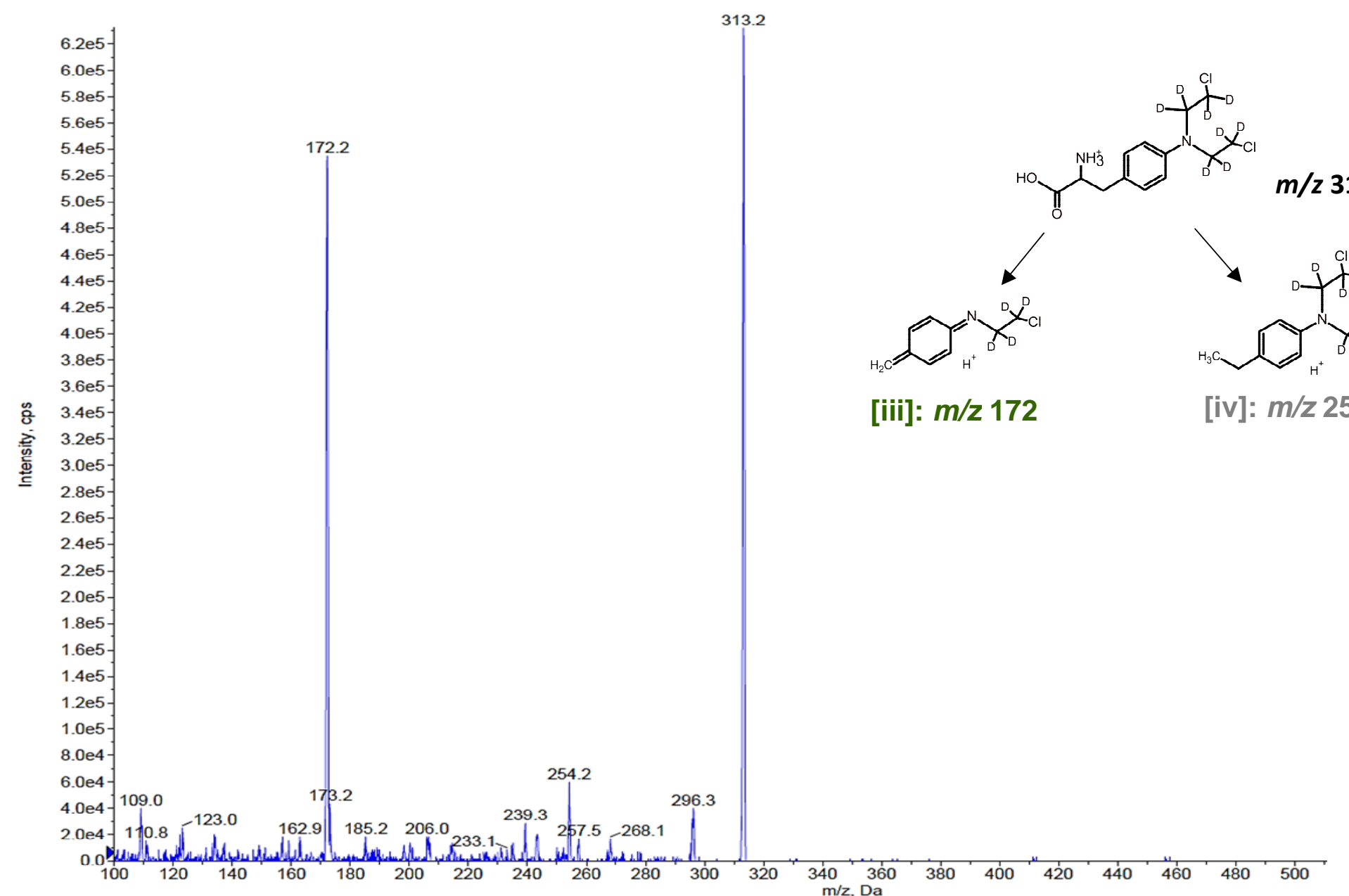

Figure 2: MSMS spectra of $[\mathrm{M}+\mathrm{H}]+$ of melphalan $(\mathrm{A})$ and the internal standatd melphalan-d8 (B), the product ions used in MRM are shown 


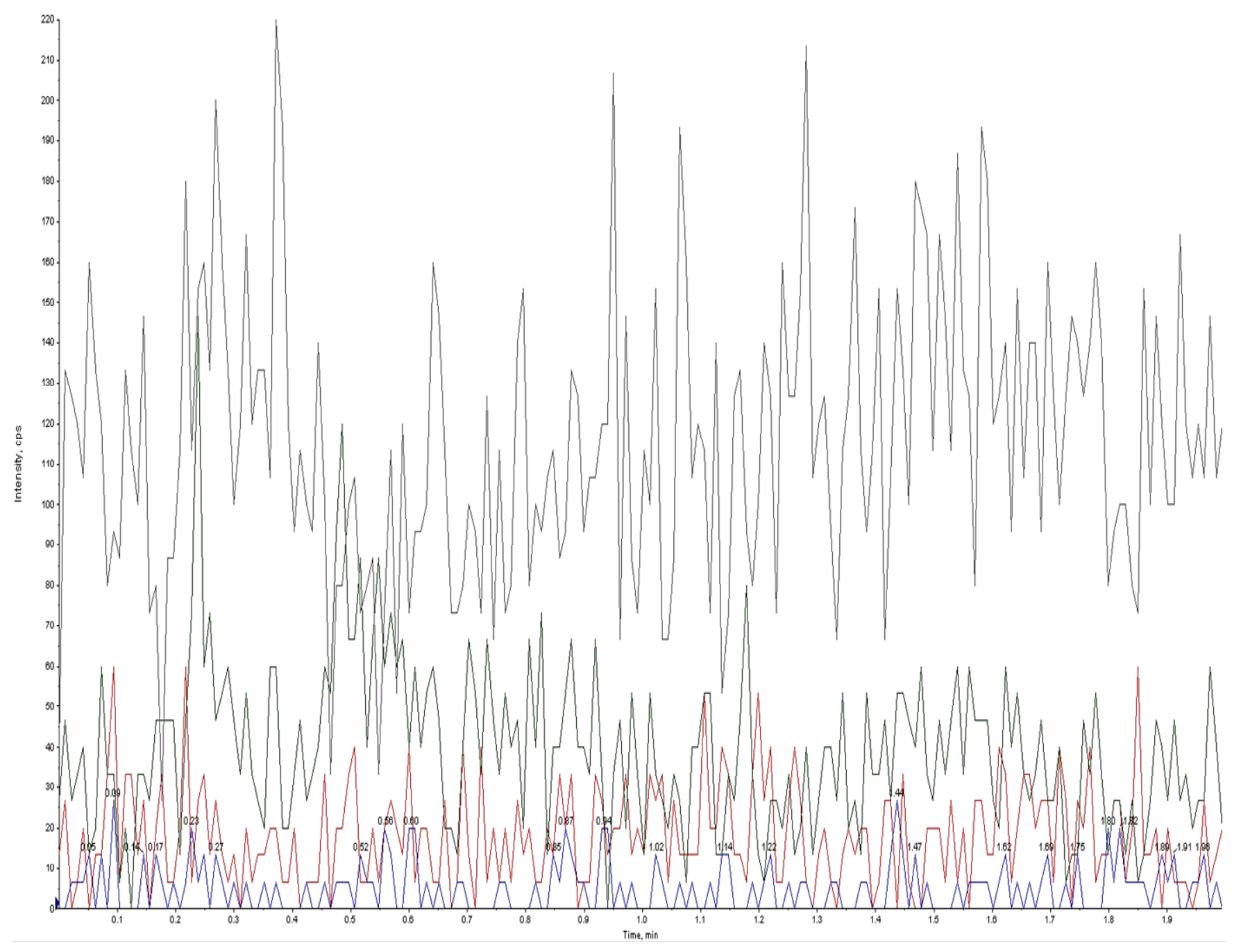

(A) 


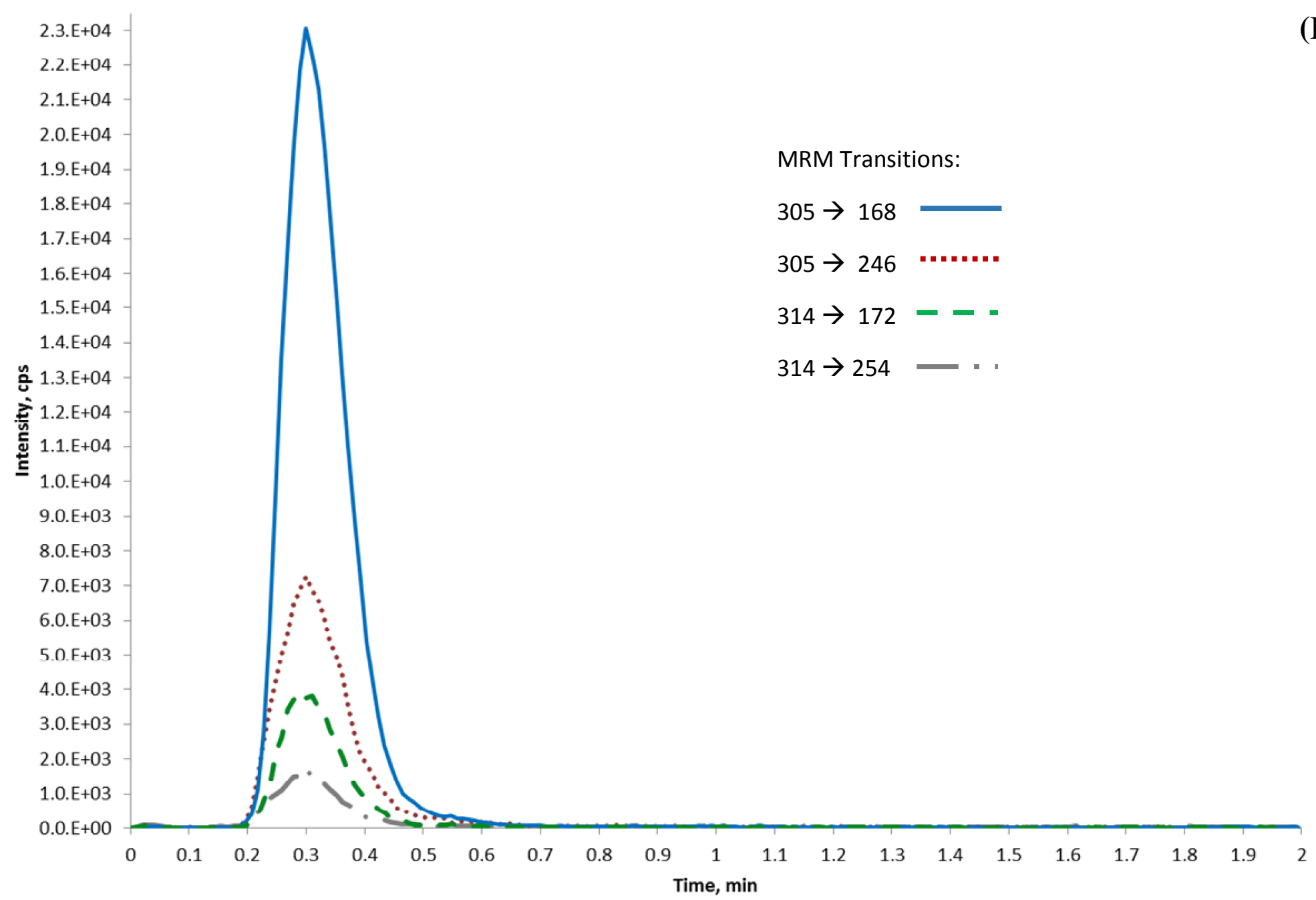

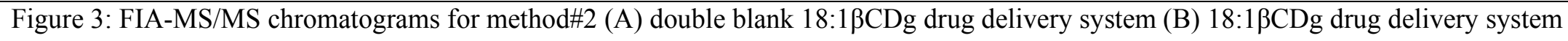
spiked with melphalan $(10 \mathrm{ng} / \mathrm{mL})$ and melphalan-d8 (40 ng/mL) 


\subsection{Linearity and sensitivity}

An 8-point standard curve was constructed (Figure 4, Method\#1) by calculating the peak area ratio of melphalan to melphalan-d8 versus melphalan concentration and establishing a linear regression analysis weighting the standard curve with $1 / \mathrm{X}$ for best fit. The average correlation coefficient $(\mathrm{n}=3)$ was found to be 0.9944 for method 1 and and 0.9991 for method 2. The LLOQ was $3 \mathrm{ng} / \mathrm{mL}$ and ULOQ was $100 \mathrm{ng} / \mathrm{mL}$. Such values are ideal for the intended application and provide the needed quantitative power to assess the solubilization potential of the novel formulations without the need for tedious chromatographic separation.

\subsection{Accuracy and precision}

The precision and accuracy were evaluated according to the FDA guidelines and are shown in Tables 3 and 4. The LQC ( $9 \mathrm{ng} / \mathrm{mL})$ was 3 fold higher than the LLOQ and the HQC was $80 \%$ of the ULOQ, as stipulated by the regulatory guidelines.

The intra-day precision and accuracy (Table 3) of the methods were evaluated by running three sets of QCs in three different days with five replicates of each QC in each run. The accuracy was reported as a percentage of the theoretical concentration ranging from 89.89 to $103.73 \%$ for method 1 and from 89.07 to $107.87 \%$ for method 2 . The precision was also within the acceptable range as the coefficient of variation $(\mathrm{CV} \%)$ was in the range of $1.69-9.35 \%$ and $0.9-10.39 \%$ for methods 1 and 2 , respectively.

Similarly, the inter-day accuracy and precision data for the 15 replicates from the three-day runs yielded a precision in range of 1.08 and $5.56 \%$ and accuracy between $93.62 \%$ and $101.56 \%$ for method \# 1. The inter-day precision and accuracy range for method \# 2 were 1.49 to 6.43 and 93.9 to $100.47 \%$ respectively (Table 4). All these values were within the acceptable range according to the FDA guidelines. 


\subsection{Stability}

Determining the chemical stability of QC samples in different storage conditions is essential for ensuring the accuracy of the method. The suitability of the experimental and storage conditions are assessed. Stability of the QC samples at bench top (stability at room temperature) for 24 hrs results showed over 50\% reduction in the initial concentration of all QC samples for both methods. This is expected as hydrolysis of melphalan is fast in an aqueous solution at room temperature. ${ }^{6,33}$ Stability of QCs in the auto-sampler (at $4{ }^{\circ} \mathrm{C}$ ) for $24 \mathrm{hrs}$ showed $30 \%$ reduction of the initial concentrations for all QCs for method\#1. For method \# 2, at auto-sampler condition $\left(4{ }^{\circ} \mathrm{C}\right)$ for $24 \mathrm{hrs}$, the precision and accuracy for the 5 replicates were $93.2 \%$ to 98.52 and 2.72 to $6.72 \%$, respectively. Such data suggests the need for quick analysis of melphalan samples to ensure no loss of the analyte during the analysis; hence the value of developing fast FIA-MS/MS method.

For the freeze-thaw stability, each batch of the QC samples was subjected to three freeze-thaw cycles. Upon the third cycle, the precision and accuracy were in the range of 93.55-102.8\% and 5.01$6.6 \%$, respectively for method\#1 in comparison to $92.67-104.22 \%$ and 3.32-6.38\% for method\#2. In both cases, the analyte was stable after three cycles of freezing and thawing, meeting the required regulatory criteria of $\pm 15 \%$.

For the long term stability ( 35 days at $-80^{\circ} \mathrm{C}$ ), the precision and accuracy failed to meet the FDA guidelines as more than 2 QCs in each level were out of the range of $15-20 \%$ for method\#1. On the contrary, the precision and accuracy of QC replicates were between 91.7 to $100.6 \%$ and 3.34 to 8.76 for method\#2. These results indicate that samples for method 2 can be stored up to one month at -80 without affecting the method's validity. Such discrepancy between the two methods is most likely due to ability of $\beta-\mathrm{CD}$ to preserve the physiochemical stability of melphalan during freezing and storage.

In summary, Method\#2, with the $18: 1 \beta \mathrm{CDg} /$ melphalan complexes, showed acceptable stability in all conditions, except for room temperature. However, significant instability was observed for method 1 . As 
a result, all experimental samples were freshly prepared and analyzed including the standard curve and QC samples to ensure the accuracy and the validity of the results. 


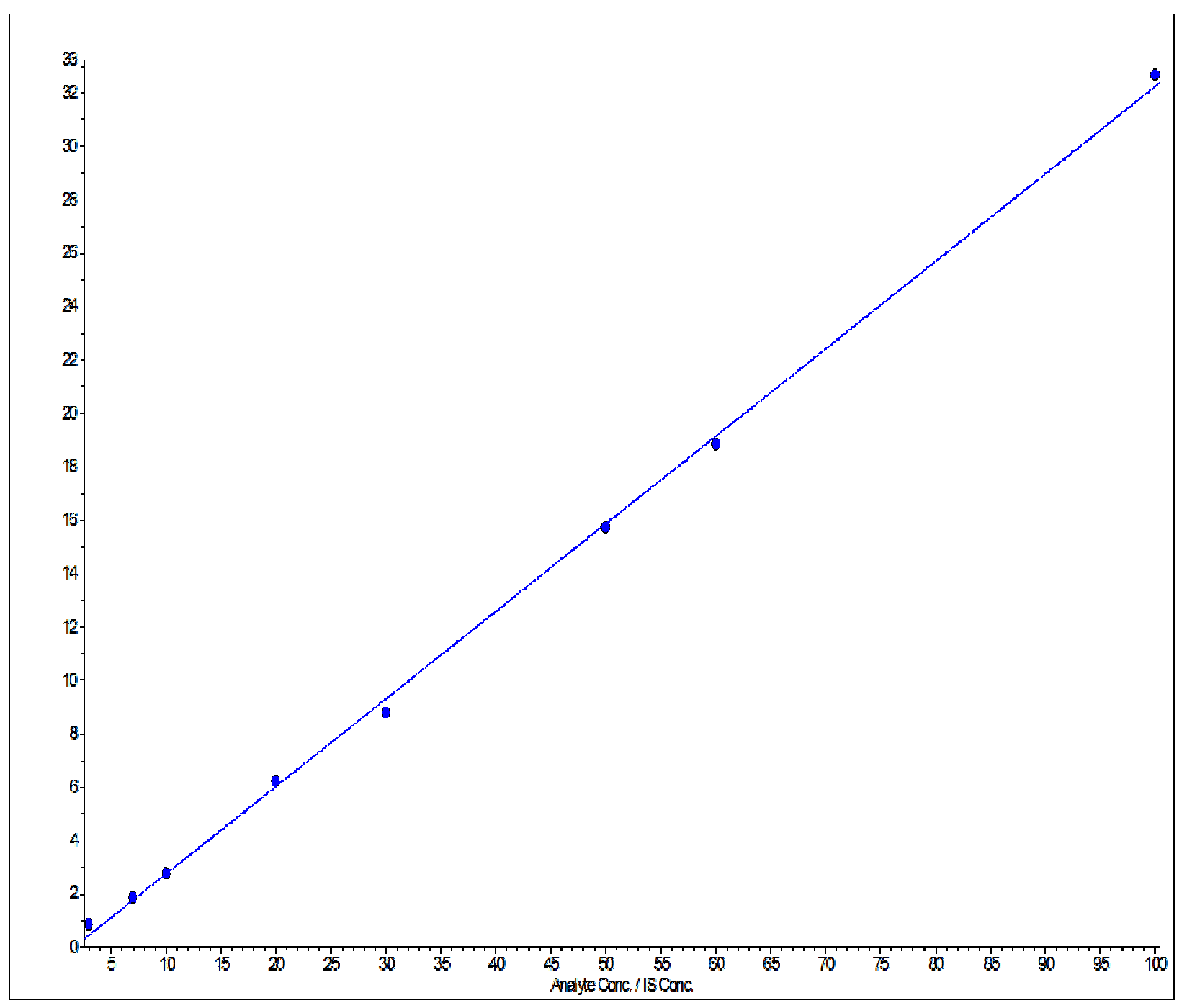

Figure 4: A typical 8 points standard curve ranging from $3 \mathrm{ng} / \mathrm{mL}$ to $100 \mathrm{ng} / \mathrm{mL}$ with a regression coefficient of 0.9995 (Method \# 1) 


\begin{tabular}{|c|c|c|c|c|c|c|c|c|}
\hline \multirow[b]{2}{*}{$\begin{array}{l}\text { QUALITY } \\
\text { CONTROL }\end{array}$} & \multirow[b]{2}{*}{ Replicates } & \multirow[b]{2}{*}{ Analysis day } & \multicolumn{3}{|l|}{ METHOD \# 1} & \multicolumn{3}{|l|}{ METHOD \# 2} \\
\hline & & & $\begin{array}{l}\text { Observed concentration } \\
(\text { mean } \pm \mathrm{SD} ; \mathrm{ng} / \mathrm{mL})\end{array}$ & $\begin{array}{l}\text { Precision } \\
\text { (RSD\%) }\end{array}$ & $\begin{array}{l}\text { Accuracy } \\
(\%)\end{array}$ & $\begin{array}{l}\text { Observed concentration } \\
(\text { mean } \pm \text { SD; ng/mL) }\end{array}$ & $\begin{array}{l}\text { Precision } \\
\text { (RSD\%) }\end{array}$ & $\begin{array}{l}\text { Accuracy } \\
(\%)\end{array}$ \\
\hline \multirow{3}{*}{$\begin{array}{l}\text { LLOQ } \\
(3 \text { NG/ML) }\end{array}$} & 5 & 1 & $2.93 \pm 0.13$ & 4.59 & 97.67 & $3.24 \pm 0.089$ & 2.73 & 107.87 \\
\hline & 5 & 2 & $3.11 \pm 0$ & 4.07 & 103.73 & $2.93 \pm 0.3$ & 10.39 & 97.60 \\
\hline & 5 & 3 & $3.10 \pm 0.08$ & 2.67 & 103.27 & $2.88 \pm 0.18$ & 6.09 & 95.93 \\
\hline \multirow{3}{*}{$\begin{array}{l}\text { LQC } \\
\text { (9 NG/ML) }\end{array}$} & 5 & 1 & $9.04 \pm 0.16$ & 1.81 & 100.44 & $8.88 \pm 0.08$ & 0.9 & 98.62 \\
\hline & 5 & 2 & $8.85 \pm 0.15$ & 1.69 & 98.311 & $8.02 \pm 0.39$ & 4.87 & 89.07 \\
\hline & 5 & 3 & $8.92 \pm 0.41$ & 4.57 & 99.13 & $8.93 \pm 0.35$ & 3.92 & 99.27 \\
\hline \multirow{3}{*}{$\begin{array}{l}\text { MQC } \\
(35 \\
\text { NG/ML) }\end{array}$} & 5 & 1 & $33.14 \pm 1.39$ & 4.21 & 94.69 & $32.48 \pm 1.79$ & 5.5 & 92.8 \\
\hline & 5 & 2 & $31.46 \pm 1.31$ & 4.18 & 89.89 & $33.42 \pm 1.94$ & 5.8 & 95.48 \\
\hline & 5 & 3 & $33.7 \pm 3.15$ & 9.35 & 96.29 & $32.7 \pm 1.50$ & 4.59 & 93.43 \\
\hline \multirow{3}{*}{$\begin{array}{l}\text { HQC } \\
(80 \\
\text { NG/ML) }\end{array}$} & 5 & 1 & $77.64 \pm 5.17$ & 6.62 & 97.05 & $78.8 \pm 4.88$ & 6.19 & 98.5 \\
\hline & 5 & 2 & $73.2 \pm 4.87$ & 1.88 & 91.5 & $78.26 \pm 3.28$ & 4.2 & 97.83 \\
\hline & 5 & 3 & $81.82 \pm 2.48$ & 3.12 & 102.27 & $80.82 \pm 2.66$ & 3.29 & 101.03 \\
\hline
\end{tabular}

[Table 3]: Intra-day accuracy and precision 


\begin{tabular}{|c|c|c|c|c|c|c|c|c|}
\hline \multirow[b]{2}{*}{$\begin{array}{l}\text { Quality } \\
\text { control }\end{array}$} & \multirow[b]{2}{*}{$\begin{array}{l}\text { Concentration } \\
(\mathrm{ng} / \mathrm{mL})\end{array}$} & \multirow[b]{2}{*}{ Replicates } & \multicolumn{3}{|l|}{ Method \# 1} & \multicolumn{3}{|l|}{ Method \# 2} \\
\hline & & & $\begin{array}{l}\text { Observed concentration } \\
(\text { mean } \pm \mathrm{SD} ; \mathrm{ng} / \mathrm{mL})\end{array}$ & $\begin{array}{l}\text { Precision } \\
\text { (RSD\%) }\end{array}$ & $\begin{array}{l}\text { Accuracy } \\
(\%)\end{array}$ & $\begin{array}{l}\text { Observed concentration } \\
(\text { mean } \pm \mathrm{SD} ; \mathrm{ng} / \mathrm{mL})\end{array}$ & $\begin{array}{l}\text { Precision } \\
\text { (RSD\%) }\end{array}$ & $\begin{array}{l}\text { Accuracy } \\
(\%)\end{array}$ \\
\hline LLOQ & 3 & 15 & $3.05 \pm 0.10$ & 3.32 & 101.56 & 3.01 & 6.43 & 100.47 \\
\hline LQC & 9 & 15 & $8.94 \pm 0.09$ & 1.08 & 99.3 & 8.61 & 5.97 & 95.65 \\
\hline MQC & 35 & 15 & $32.77 \pm 1.17$ & 3.56 & 93.62 & 32.87 & 1.49 & 93.9 \\
\hline HQC & 80 & 15 & $77.55 \pm 4.31$ & 5.56 & 96.94 & 79.29 & 1.7 & 99.12 \\
\hline
\end{tabular}

[Table 4]: Inter-day accuracy and precision 


\subsection{Application}

Both methods described above were utilized to characterize and evaluate the $18: 1 \beta C D g$ delivery system as a potential carrier for melphalan. $\beta-\mathrm{CD}$ has the ability to form an inclusion complex with hydrophobic drugs. ${ }^{16}$ This property of $\beta-\mathrm{CD}$ has been employed widely in the pharmaceutical industry to increase the aqueous solubility of hydrophobic moieties with several $\beta$-CD-based formulations available in the market, such as VFEND ${ }^{\circledR}$ (voriconazole, an azole antifungal agent) and NEXTERONE ${ }^{\circledR}$ (amiodarone, an antiarrhythmic medication) among others, and hundred in clinical trials. ${ }^{16}$ Previously, our group reported that the $\beta C D$ modified gemini surfactant (12 $\beta$ CDgemini) are capable of forming guest/host complexes with a hydrophobic anticancer molecule. ${ }^{18}$

To investigate the efficiency of the novel $18: 1 \beta C D g$ drug delivery system in increasing the solubility of melphalan, the validated methods were applied (Figure 5). 18:1ßCDg\Mel complexes were prepared in different $\beta$-CD gemini (host) to melphalan (guest) molar ratios. At [0:1] ratio (i.e., without the use of $18: 1 \beta C D g$ ) the aqueous solubility of melphalan was $203 \pm 16.60 \mu \mathrm{g} / \mathrm{mL}$ as determined by method $\# 1$. Increasing the molar ratio to [1:1] resulted in an almost $85 \%$ increase in melphalan's solubility $(377 \pm 16.4 \mu \mathrm{g} / \mathrm{mL})$. The highest level of solubilization was achieved when the $18: 1 \beta C D \mathrm{~g}$ to Mel molar ratios was at [2:1], with melphalan solubility reaching $605 \pm 5 \mu \mathrm{g} / \mathrm{mL}$ which is more than two-fold increase compared to melphalan aqueous solution. Upon increasing the molar ratio above [2:1], a substantial reduction in melphalan's solubility was observed at $450 \pm 6.5 \mu \mathrm{g} / \mathrm{mL}$ and $507 \pm 25.2 \mu \mathrm{g} / \mathrm{mL}$ for [4:1] and [5:1] molar ratios, respectively. We propose that at [2:1] 18:1 $\beta \mathrm{CDg} \backslash \mathrm{Mel}$ molar ratio, two $18: 1 \beta \mathrm{CDg}$ molecules encapsulate one melphalan molecule forming stable inclusion complexes leading to the higher solubilizing effect. This result is in support of the previous model proposed by our group. ${ }^{18}$ 


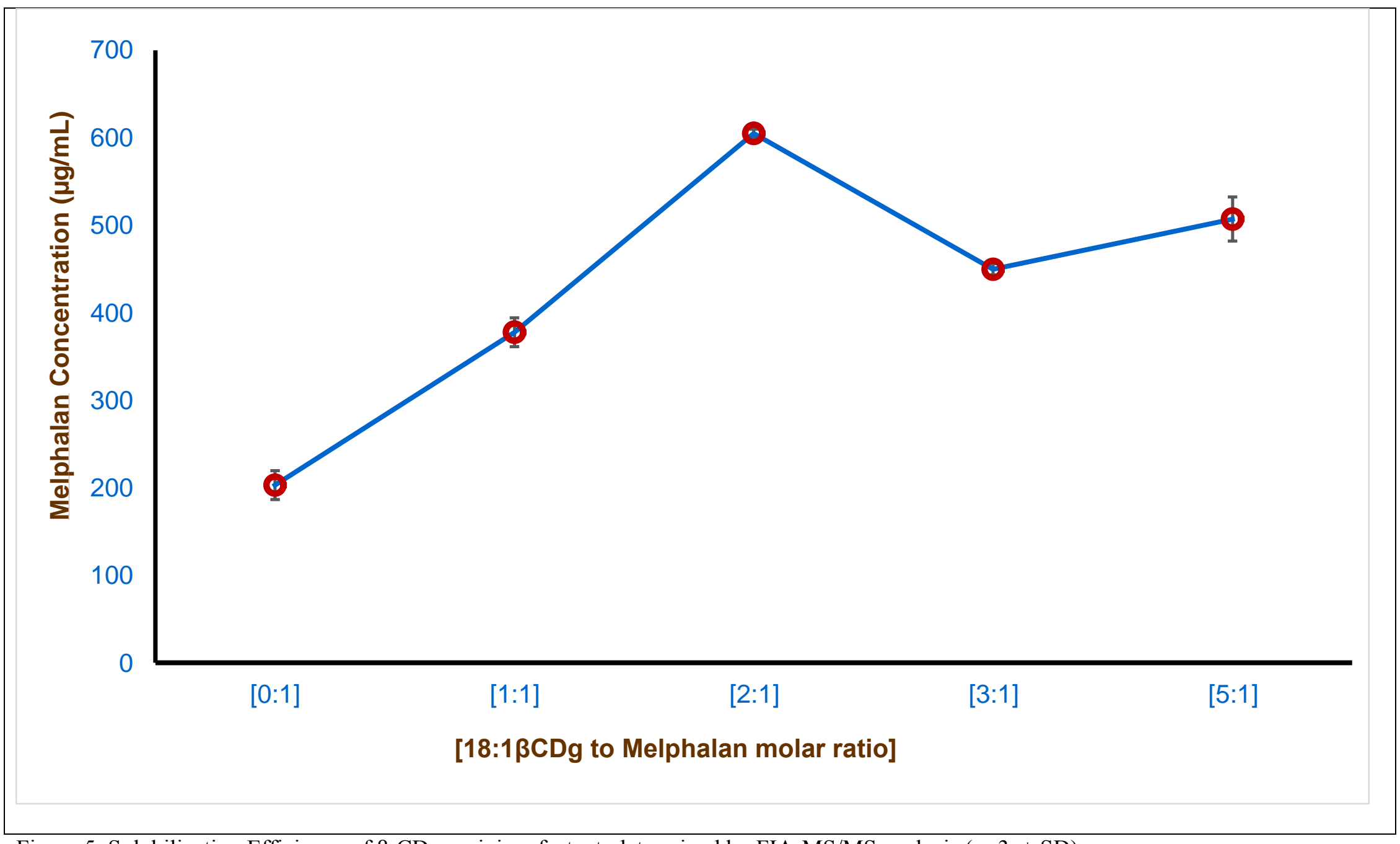

Figure 5: Solubilization Efficiency of $\beta$-CD-gemini surfactant: determined by FIA-MS/MS analysis $(\mathrm{n}=3, \pm$ SD) 


\section{Conclusion}

In this study, two FIA-MS/MS methods for melphalan were successfully developed and validated. The methods were applied for the determination of melphalan in novel 18:1 $\beta \mathrm{CDg}$ drug delivery system. The simplicity and speed of the methods were appropriate with the requirement of efficient analytical approaches to quantify highly unstable drugs such as melphalan. In fact, to process a batch of 96 samples will only require 5.6 hours and we demonstrated that the samples are stable in such timeframe within an autosampler of an HPLC system. The removal of the HPLC column did not affect the sensitivity, accuracy, and precision of the methods as they were validated according to FDA guidelines. An important finding that could have been overlooked if a full validation was not conducted is the stability of the samples. It was shown that fresh samples should be prepared and analyzed as various storage conditions resulted in degradation beyond the acceptable limit of $15 \%$.

The sensitivity and specificity of the methods allowed for the characterization of the solubility efficiency of a novel $\beta$-CD conjugated drug delivery system and it was shown that the solubility was significantly enhanced by $18: 1 \beta C D g$ delivery system. Such findings are critical as increasing the solubility of melphalan will enhance the bioavailability of the drug in a biological system and improve its chemotherapeutic effects. In addition, the results provide essential data in understanding the basic behavior governing the use of the novel drug delivery system, $18: 1 \beta C D g$ surfactants. Currently, the pharmacokinetics of the formulation is being assessed in animal model using FIA-MS/MS and it will be reported upon completion.

Acknowledgments: The authors acknowledge funding to purchase the 4000 QTRAP LC/MS/MS system from the Canada Foundation for Innovation (CFI). The project was supported by a Natural Sciences and Engineering Research Council of Canada (NSERC) -Discovery grant. The authors acknowledge the help of Ms. Mona Khamis, College of Pharmacy and Nutrition, regarding method validation. 


\section{References}

1. Savjani KT, Gajjar AK, Savjani JK. Drug solubility: importance and enhancement techniques. ISRN pharmaceutics 2012;2012.

2. Neidle S, Thurston DE. Chemical approaches to the discovery and development of cancer therapies. Nature Reviews Cancer 2005;5:285-96.

3. Rinaki E, Valsami G, Macheras P. Quantitative biopharmaceutics classification system: the central role of dose/solubility ratio. Pharmaceutical research 2003;20:1917-25.

4. Testori A, Verhoef C, Kroon HM, et al. Treatment of melanoma metastases in a limb by isolated limb perfusion and isolated limb infusion. Journal of surgical oncology 2011;104:397-404.

5. Zar T, Graeber C, Perazella MA. Reviews: recognition, treatment, and prevention of propylene glycol toxicity. Seminars in dialysis 2007;20:217-9.

6. Stout SA, Riley CM. The hydrolysis of L-phenylalanine mustard (melphalan). International journal of pharmaceutics 1985;24:193-208.

7. Ajazuddin, Alexander A, Amarji B, Kanaujia P. Synthesis, characterization and in vitro studies of pegylated melphalan conjugates. Drug development and industrial pharmacy 2013;39:1053-62.

8. Peyrode C, Weber V, David E, et al. Quaternary ammonium-melphalan conjugate for anticancer therapy of chondrosarcoma: in vitro and in vivo preclinical studies. Investigational new drugs 2012;30:1782-90.

9. Rajpoot P, Bali V, Pathak K. Anticancer efficacy, tissue distribution and blood pharmacokinetics of surface modified nanocarrier containing melphalan. International journal of pharmaceutics 2012;426:219-30.

10. Vodovozova E, Kuznetsova N, Kadykov V, Khutsyan S, Gaenko G, Molotkovsky YG. Liposomes as nanocarriers of lipid-conjugated antitumor drugs melphalan and methotrexate. Nanotechnologies in Russia 2008;3:228-39.

11.Farokhzad OC, Langer R. Impact of nanotechnology on drug delivery. ACS nano 2009;3:16-20.

12.Ma DQ, Rajewski RA, Stella VJ. New injectable melphalan formulations utilizing (SBE) $7 \mathrm{~m}-\beta-\mathrm{CD}$ or HP- $\beta$-CD. International journal of pharmaceutics 1999;189:227-34.

13.Loftsson T, Björnsdóttir S, Pálsdóttir G, Bodor N. The effects of 2-hydroxypropyl- $\beta$-cyclodextrin on the solubility and stability of chlorambucil and melphalan in aqueous solution. International journal of pharmaceutics 1989;57:63-72.

14. Koltun M, Morizzi J, Katneni K, Charman SA, Shackleford DM, McIntosh MP. Preclinical comparison of intravenous melphalan pharmacokinetics administered in formulations containing either (SBE) $7 \mathrm{~m}-\beta$-cyclodextrin or a co-solvent system. Biopharmaceutics \& drug disposition 2010;31:450-4.

15.Hari PN, Ajitawi O, Arce-Lara C, et al. Results of a Phase II Study of Propylene Glycol (PG)-Free, Captisol-Enabled Melphalan Conditioning for Autologous Hematopoietic Stem Cell Transplantation 
(AHCT) in Patients with Multiple Myeloma (MM). Biology of Blood and Marrow Transplant 2015;21:S138.

16. Challa R, Ahuja A, Ali J, Khar R. Cyclodextrins in drug delivery: an updated review. Aaps Pharmscitech 2005;6:E329-E57.

17. Bombelli C, Giansanti L, Luciani P, Mancini G. Gemini surfactant based carriers in gene and drug delivery. Current medicinal chemistry 2009;16:171-83.

18. Poorghorban M, Karoyo AH, Grochulski P, Verrall RE, Wilson LD, Badea I. A 1H NMR Study of Host/Guest Supramolecular Complexes of a Curcumin Analogue with $\beta$-Cyclodextrin and a $\beta$ Cyclodextrin-Conjugated Gemini Surfactant. Molecular pharmaceutics 2015;12:2993-3006.

19.Poorghorban M, Das U, Alaidi O, et al. characterization of the host-guest complex of a curcumin analog with $\beta$-cyclodextrin and $\beta$-cyclodextrin-gemini surfactant and evaluation of its anticancer activity. International journal of nanomedicine 2015;10:503.

20.Donkuru M, Chitanda JM, Verrall RE, El-Aneed A. Multi-stage tandem mass spectrometric analysis of novel $\beta$-cyclodextrin-substituted and novel bis-pyridinium gemini surfactants designed as nanomedical drug delivery agents. Rapid Communications in Mass Spectrometry 2014;28:757-72.

21. Michel D, Chitanda JM, Balogh R, et al. Design and evaluation of cyclodextrin-based delivery systems to incorporate poorly soluble curcumin analogs for the treatment of melanoma. European Journal of Pharmaceutics and Biopharmaceutics 2012;81:548-56.

22. Michel D, Mohammed-Saeid W, Getson H, et al. Evaluation of $\beta$-cyclodextrin-modified gemini surfactant-based delivery systems in melanoma models. International Journal of Nanomedicine 2016;11:6703-12.

23. Higuchi T, Connors A. Phase-solubility techniques. Advances in Analytical Chemistry and Instrumentation 1965;4:117-210.

24.Chang S, Alberts D, Melnick L, WaLson PD, Salmon S. High-pressure liquid chromatographic analysis of melphalan in plasma. Journal of pharmaceutical sciences 1978;67:679-82.

25.Davis TP, Peng Y-M, Goodman GE, Alberts DS. HPLC, MS, and pharmacokinetics of melphalan, bisantrene and 13-cis retinoic acid. Journal of chromatographic science 1982;20:511-6.

26. Gouyette A, Hartmann O, Pico J-L. Pharmacokinetics of high-dose melphalan in children and adults. Cancer chemotherapy and pharmacology 1986;16:184-9.

27. Brightman K, Finlay G, Jarvis I, Knowlton T, Manktelow C. A stability-indicating method for the determination of melphalan and related impurity content by gradient HPLC. Journal of pharmaceutical and biomedical analysis 1999;20:439-47.

28. Adair C, Burns D, Crockard A, Desai Z, Harriott M. Modified extraction and chromatography for the measurement of plasma melphalan by ion-pair high-performance liquid chromatography. Journal of Chromatography B: Biomedical Sciences and Applications 1984;336:429-33. 
29.Cummings J, MacLellan A, Smyth JF, Farmer PB. Determination of reactive nitrogen mustard anticancer drugs in plasma by high-performance liquid chromatography using derivatization. Analytical chemistry 1991;63:1514-9.

30.Pinguet F, Joulia JM, Martel P, Grosse PY, Astre C, Bressolle F. High-performance liquid chromatographic assay for melphalan in human plasma Application to pharmacokinetic studies. Journal of Chromatography B: Biomedical Sciences and Applications 1996;686:43-9.

31.De Boeck G, Van Cauwenberghe K, Eggermont A, Van Oostertom A, De Bruijn E. Determination of melphalan and hydrolysis products in body fluids by GC-MS. Journal of High Resolution Chromatography 1997;20:697-700.

32. Davies I, Allanson J, Causon R. Rapid determination of the anti-cancer drug Melphalan (AlkeranTM) in human serum and plasma by automated solid phase extraction and liquid chromatography tandem mass spectrometry. Chromatographia 2000;52:S92-S7.

33. Mirkou A, Vignal B, Cohen S, Guillaumont M, Glehen O, Guitton J. Assays for the quantification of melphalan and its hydrolysis products in human plasma by liquid chromatography-tandem mass spectrometry. Journal of Chromatography B 2009;877:3089-96.

34. Bauer TW, Gutierrez M, Dudrick DJ, et al. A human melanoma xenograft in a nude rat responds to isolated limb perfusion with TNF plus melphalan. Surgery 2003;133:420-8.

35.Sparidans RW, Martens I, Valkenburg-van Iersel LB, den Hartigh J, Schellens JH, Beijnen JH. Liquid chromatography-tandem mass spectrometric assay for the PARP-1 inhibitor olaparib in combination with the nitrogen mustard melphalan in human plasma. Journal of Chromatography B 2011;879:1851-6.

36. Michel D, Gaunt MC, Arnason T, El-Aneed A. Development and validation of fast and simple flow injection analysis-tandem mass spectrometry (FIA-MS/MS) for the determination of metformin in dog serum. Journal of pharmaceutical and biomedical analysis 2015;107:229-35.

37. Song F, Monroe D, El-Demerdash A, Palmer C. Screening for multiple weight loss and related drugs in dietary supplement materials by flow injection tandem mass spectrometry and their confirmation by liquid chromatography tandem mass spectrometry. Journal of pharmaceutical and biomedical analysis 2014;88:136-43.

38. Mičová K, Friedecký D, Faber E, Polýnková A, Adam T. Flow injection analysis vs. ultra high performance liquid chromatography coupled with tandem mass spectrometry for determination of imatinib in human plasma. Clinica Chimica Acta 2010;411:1957-62.

39. Carducci C, Santagata S, Leuzzi V, et al. Quantitative determination of guanidinoacetate and creatine in dried blood spot by flow injection analysis-electrospray tandem mass spectrometry. Clinica chimica acta 2006;364:180-7.

40. Chen X, Gu Q, Qiu F, Zhong D. Rapid determination of metformin in human plasma by liquid chromatography - tandem mass spectrometry method. Journal of Chromatography B 2004;802:37781 .

41. Marques MAS, de Souza Soares A, Pinto OW, et al. Simple and rapid method determination for metformin in human plasma using high performance liquid chromatography tandem mass 
spectrometry: Application to pharmacokinetic studies. Journal of Chromatography B 2007;852:30816.

42. Kolev SD, McKelvie ID. Advances in flow injection analysis and related techniques: Elsevier; 2008.

43. Ruzicka J, Hansen EH. Retro-review of flow-injection analysis. TrAC Trends in Analytical Chemistry 2008;27:390-3.

44. COMMUNITIES TCOTE. Implementing Council Directive 96/23/EC concerning the performance of analytical methods and the interpretation of results 2002.

45. Administration FaD. FDA guidance for industry: bioanalytical method validation. Rockville, MD: US Department of Health and Human Services. Food and Drug Administration, Center for Drug Evaluation and Research 2001;1:124-9. 